\title{
Morphine Effects on the Spontaneous Electroencephalogram in Polydrug Abusers: Correlations with Subjective Self-Reports
}

\author{
Robert L. Phillips, Ph.D., Ronald Herning, Ph.D., and Edythe D. London, Ph.D.
}

The spontaneous electroencephalogram (EEG) was recorded after the intramuscular (IM) injection of morphine sulfate $(15,30 \mathrm{mg})$ or saline $(0.9 \% \mathrm{NaCl})$. Correlations between changes in EEG spectral power and subjective self-reports, as measured on subscales of the Addiction Research Center Inventory (ARCI), were evaluated. Morpinine increased alpha 1 and alpha 2 power and theta power, and attenuated the increase in delta power observed after placebo. Positive correlations were found between the change in alpha $a_{1}$, alpha $a_{2}$, beta $a_{1}$, and beta $a_{2}$ power in response to $30 \mathrm{mg}$ of morphine and scores on Morphine-Benzedrine Group (MBG) subscale of the $A R C I$. Negative relationships were observed between changes in alpha $a_{1}$ and beta $a_{2}$ and scores on the Pentobarbital Chlorpromazine Alcohol Group (PCAG) subscale. The findings indicate that positive subjective effects of opioids, as measured by the MBG subscale, are related to increases in alpha and beta activity and are associated with reduction of opioid-induced sedation, as measured by the PCAG subscale.

[Neuropsychopharmacology 10:171-181, 1994]
KEY WORDS: Electroencephalography; Morphine; Opiate; Reinforcement; Drug abuse

The subjective effects of opioids have been studied extensively in human volunteers(Martin 1983). Morphine produces a wide variety of effects, including analgesia, drowsiness, changes in mood, and mental clouding (Jaffe and Martin 1985). In detoxified volunteers with histories of opioid abuse, arousal is produced (Kay et al. 1969), mental clouding is less prominent, and positive effects on mood are more pronounced than in nor-

From the Neuroimaging and Drug Action Section, Neuroscience Branch (RLP, EDL) and the Medical Affairs Branch (RH), Addiction Research Center, National Institute on Drug Abuse, National Institutes of Health, Baltimore, Maryland; and Department of Radiology (EDL), the Johns Hopkins Medical Institutions and Department of Pharmacology and Experimental Therapeutics, School of Medicine, University of Maryland, Baltimore, Maryland.

Address correspondence to: Edythe D. London, Ph.D., Chief, Neuroimaging and Drug Action Section, NIDA Addiction Research Center, P.O. Box 5180, Baltimore, Maryland 21224.

Received August 18, 1993; revised December 28, 1993; accepted January 3, 1994. mal subjects (von Felsinger et al. 1955). Although considerable information about the actions of opioid drugs in the nervous system exists, little is known about the central mechanisms underlying their effects on mood and feeling state in human subjects.

Effects of morphine on the electroencephalogram (EEG) have been tested in several species. In rats, opioids increase the abundance of low frequencies in the EEG (Wikler 1954; Khazan and Colasanti 1971; Young et al. 1980; Young and Khazan 1984, 1986). In the dog, periods of burst-slow activity have been observed (Wikler 1952). Slowing of the EEG is observed in the cat as well (De Andrés and Caballero 1989).

Opioid-induced slowing of the EEG in human subjects was first discovered by visual observation of EEG tracings (Berger 1937; Andrews 1941, 1943; Gibbs and Maltby 1943). Slowing has been defined in several ways. Earlier studies defined slowing as a decrease in the dominant frequency of the EEG tracings (Fig. 1a) or as the appearance of bursts of slow wave activity (Fig. 1b). Later studies using more quantitative methods defined slowing as a decrease in the alpha frequency (Fig. 1c) 


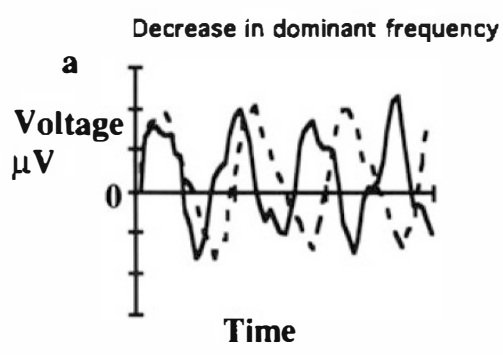

(sec)

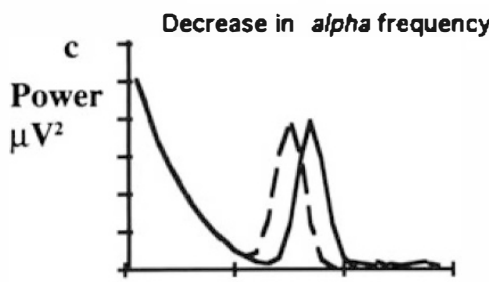

Frequency

(Hz)

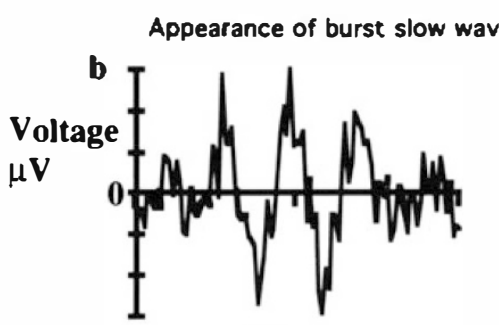

Time

(sec)

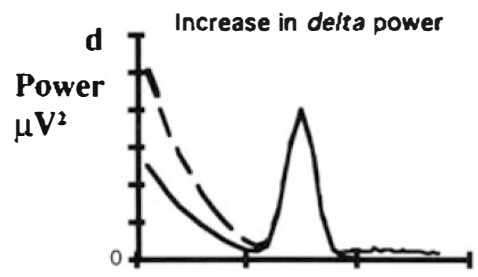

Frequency

(Hz)

"Slowed"

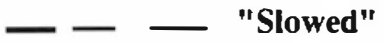

or as an increase in low frequency (delta and/or theta) power (Fig. 1d). A decrease in the dominant frequency of the EEG tracing can be due either to a decrease in alpha frequency, a decrease in alpha power relative to delta and/or theta power, or an increase in delta and/or theta power (Lukas 1991).

Effects of opioids on the EEG of human subjects with a history of opioid abuse have been reported. Both heroin and methadone decreased alpha frequency and increased delta and theta abundance (Fink et al. 1971; Volavka et al. 1979). Biphasic EEG effects of intravenous heroin have been reported. Increased alpha power and decreased alpha frequency were found during the first 2 to 3 minutes; after 3 to 5 minutes, a decrease in alpha amplitude and an increase in theta abundance occurred (Volavka et al. 1970). Kay et al. (1969) reported diminished amplitude of delta waves with an increased incidence of unusual EEG patterns such as bursts of multiple frequency waves and mixtures of alpha and delta.

Effects of opioids on the EEG vary with the drug histories of the subjects. In surgical patients, the injectable opioid anesthetics, fentanyl, sufentanil, and alfentanil, increased abundance of EEG delta power and decreased abundance of alpha and/or beta power (Sebel et al. 1981; Bovill et al. 1983; Smith et al. 1984; Wauquier et al. 1984; Bromm et al. 1989; Scott et al. 1991). In contrast, in normal, pain-free human subjects, a small decrease in delta, an increase in slow alpha with a decrease in relative fast alpha, and an increase in beta power occurred 1 to 2 hours after subcutaneous administration of morphine (4 and $8 \mathrm{mg}$ ) (Matejcek et al. 1988).
These changes were accompanied by significant increases in self-reports of drowsiness, lethargy, and mental slowness. Opioid-naive subjects gave self-reports of being dizzy, nauseous, itchy, warm, and headachy more often in response to morphine than to placebo (Beecher 1959).

Despite differences in the specific opioid drugs and doses and populations tested, increased EEG slowwave activity (delta and/or theta abundance) has been the common response to opioids in human subjects. However, there has been no previous attempt to correlate the magnitude of EEG changes after opioid drug treatment to scores of mood and feeling state. In the present study, self-reports of mood and feeling state were correlated with the quantitative changes in the EEG produced by morphine in polydrug abusers with histories of opioid use and dependence.

\section{MATERIALS AND METHODS}

\section{Subjects}

Subjects were paid volunteers who resided on a closed research ward for the duration of the study. Nineteen subjects enrolled in the study, but data were only available for twelve. EEG data from seven of the subjects was not retained either because of equipment failure or because the subjects had subjective responses that were not characteristic of polysubstance abusers that are enrolled in studies at the Addiction Research Center (i.e., extremely weak response to $30 \mathrm{mg}$ intramuscular (IM) morphine or strong response to placebo). The 
Table 1. Effects of Morphine on Visual Analog Scale (VAS) Responses

\begin{tabular}{llcc}
\hline VAS Question & Saline & $\begin{array}{c}\text { Morphine } \\
\text { (15 mg) }\end{array}$ & $\begin{array}{c}\text { Morphine } \\
\text { (30 mg) }\end{array}$ \\
\hline How strong is the drug effect? $^{+\S}$ & $5(7)$ & $32(19)$ & $54(18)$ \\
Does the drug have good effects? $^{+\S}$ & $4(6)$ & $32(18)$ & $59(22)$ \\
Does the drug have bad effects? $_{\text {How much do you like the drug? }}^{+\S}$ & $4(5)$ & $7(7)$ & $13(17)$ \\
How high do you feel? $^{+\S}$ & $4(6)$ & $38(24)$ & $59(28)$ \\
How much do you want to take the drug again? $^{\dagger}$ & $4(6)$ & $29(17)$ & $57(21)$ \\
\end{tabular}

\footnotetext{
Numerical columns with mean (SD).

+ Significant main effects of treatment $(p<.0001)$ by repeated-measures ANOVA.

$\S$ Response to $30 \mathrm{mg}$ morphine significantly different from response to $15 \mathrm{mg}$ morphine, $p<.05$ by Bonferroni-corrected $t$-test.
}

remaining 12 subjects were $26-39$ years of age (mean $=35 ; \mathrm{SD}=4.5$ ).

A recent history of intravenous usage of opioids was a criterion for admission. The time from the last use of opioids prior to admission to the study was 3 (4) (mean [SD]) weeks. Subjects were confirmed to be opiate-free by urine testing prior to admission and while in the study. Screening instruments included the National Institute of Mental Health (Bethesda, MD) Diagnostic Interview Schedule (Robins et al. 1981), as modifed for computerized administration. Full details of the screening process are presented elsewhere (London et al. 1990). All but one subject met DSM-III (1980) criteria for opioid dependence, although none showed signs of physical dependence at the time of admission or during participation in the study. Most other diagnoses for which Axis I criteria were met related to substance abuse disorders; however, one subject met criteria for psychosexual dysfunction, one met criteria for simple phobia, and two met criteria for agoraphobia. Axis II diagnoses of borderline personality disorder (one subject) and antisocial personality disorder (three subjects) were also allowed.

All subjects gave informed consent to the procedures in the protocol, which was approved by the Institutional Review Boards of Johns Hopkins Medical Institutions and Francis Scott Key Medical Center, where the NIDA Addiction Research Center is located.

\section{Drug Treatments}

Morphine sulfate (Mallinckrodt, Paris, KY) was dissolved in $0.9 \% \mathrm{NaCl}$ at a concentration of either 15 or $30 \mathrm{mg} / \mathrm{ml}$ as the salt. The control vehicle was $0.9 \% \mathrm{NaCl}$. Doses of morphine were presented in ascending order to reduce the chance of untoward effects. A saline control session was randomly inserted in the sequence. Administration was by IM injection in a volume of $1 \mathrm{ml}$. The test compounds were administered double-blind. The doses were selected from previous data showing that $60 \%$ and $95 \%$ of detoxified, previously opioiddependent, human subjects could correctly discriminate $15 \mathrm{mg}$ and $30 \mathrm{mg}$ of morphine IM as an opioid drug rather than a sedative or marijuana (Kay et al. 1967).

\section{Test Sessions}

Subjects were administered the Morphine-Benzedrine Group (MBG); Pentobarbital Chlorpromazine Alcohol Group (PCAG); and lysergic acid diethylamide (LSD) subscales of the Addiction Research Center Inventory (ARCI) (Jasinski et al. 1967; Haertzen 1974) and the Single Dose Questionnaire (SDQ) (Fraser et al. 1961; Jasinski et al. 1971). The MBG subscale consists of 16 questions, which relate primarily to positive effects on mood. The PCAG subscale primarily measures sedation and lethargy. The LSD subscale is sensitive to weird feelings, disorientation, and increased awareness of bodily sensations. The SDQ consists of questions relating to the identification and liking of drugs. Subjects also rated the strength of the treatment effect and their liking of it on six 100-mm visual line analog scales (VAS) similar to those used by others (Preston et al. 1988). The six questions from the VAS are listed in Table 1. These questionnaires were administered 45 minutes after injection of the test compound.

During the 45-minute measurement of spontaneous EEG, the subject was blindfolded and listened to a tape of white noise on which was recorded a beep tone at 1-minute intervals. At the sounding of this tone, the subject was to respond to the question "How high do you feel?" on a scale of 0 ("no effect") to 4 ("extremely"). Pupillary diameter was measured from photographs taken of the subject's eyeball at 30 minutes before injection of the test compound (before the blindfold was applied) and at 45 minutes after injection of the test compound (after the blindfold had been removed). Pulse and blood pressure were measured 60 and 30 minutes before and 10, 20, and 45 minutes after injection of the test compound. 


\section{EEG Recording}

Electrodes made of $\mathrm{Ag} / \mathrm{AgCl}$ (Beckman Instruments, Irvine, CA) were attached to the scalp by collodion or adhesive collars according to the international ten twenty system (Jasper 1958). All montages included leads $F_{3}, F_{4}, F_{7}, F_{8}, T_{3}, T_{4}, C_{3}, C_{4}, O_{1}, O_{2}, P_{3}$, and $P_{4}$. Some also included leads $C_{z}, F_{p z}, F_{z}, P_{z}, O_{z}, T_{5}, T_{6}, F_{p 1}$, and $\mathrm{F}_{\mathrm{p} 2}$. All leads were referenced to the left ear (A1). Eight subjects had 12-lead montages; the last four subjects had 21-lead montages. Data from only the twelve leads common to all subjects were used for analysis.

Data from eight of the subjects were recorded in analog mode using an FM tape recorder at a recording speed of 15/16 inches/second, and subsequently were digitized into a computer off-line. Data from the last four subjects were digitized directly, using a different computerized system. In all cases, the data were digitized at 200 samples/second/channel. The data were acquired for a 3-minute period before injection (baseline) and for a 45-minute period starting immediately after administration of the test compound.

Digitized EEG data were reformatted using programs written by one of the authors (RLP) for use in the EEGSYS software system (Friends Medical Science Research Center, Baltimore, MD). The data were screened by a blinded, trained technician for artifacts due to eye motion or facial motion, using the DIS program of the EEGSYS software. Such artifacts generally occurred in conjunction with the "beep" prompts. During some recording sessions, one or moreleads became detached. When this occurred, data from that lead were rejected, but data from other leads were used.

An autoregressive filter (Coppola 1979) with a time constant of $200 \mathrm{msec}$. was used to remove low frequency harmonics from the remaining data. The effect of the filter was to reduce power at frequencies $<0.5 \mathrm{~Hz}$ by at least a factor of 2, while not appreciably affecting power at frequencies $>1 \mathrm{~Hz}$. The data were analyzed using a 2.56-second (512-data point) epoch by fast Fourier transform. The resulting spectra were averaged over 3-minute intervals. The power spectra were summed to form banded data based on frequency $(f)$ as follows: delta $(1 \leqslant f<6 \mathrm{~Hz})$, theta $(6 \leqslant f<8.5 \mathrm{~Hz})$, alpha $(8.5 \leqslant$ $f<10.5 \mathrm{~Hz})$, alpha $2(10.5 \leqslant f<12.5 \mathrm{~Hz})$, beta $1(12 \leqslant f<$ $18.5 \mathrm{~Hz})$ and beta $_{2}(21 \leqslant f<30 \mathrm{~Hz})$. The selection of bands was based on previous results showing that these bands reduce the amount of data without sacrificing useful drug-related information (Coppola and Hermann 1987). Finally, the data were transformed to percent change from baseline. The power-weighted mean frequency within each frequency band was also calculated.

\section{Analysis}

Self-reports of mood and feeling state (on MBG, PCAG, LSD subscales of ARCI and on VAS) were tested for significant effects of drug by a one-way repeated measures analysis of variance (ANOVA). When a significant effect of drug was found, post hoc tests using matchedpair $t$-tests with a Bonferroni correction were performed to assess significance of differences between placebo and each dose of morphine and between the two doses of morphine (three $t$-tests per variable).

Data on spectralized abundance were analyzed by a three-way ANOVA (LEAD $\times$ TIME $\times$ TREATMENT) for each spectral band using the SAS (SAS Institute, Cary, NC) procedure GLM (General Linear Models). A second set of analyses were performed in a mixed ANOVA $($ LEAD $\times$ TIME $\times$ TREATMENT) and regression (MBG, LSD, or PCAG score) analysis. The mixed ANOVA calculated an overall significance of the regression analysis used to determine correlations between the two types of continuous variables. The analyses treated TIME as a repeated measure and all other effects as between-subjects factors. Data used in the LEAD factor were from the 12 leads common to all subjects. The probability $(p)$ values were adjusted using the Greenhouse-Geisser correction where appropriate.

Post hoc Bonferroni-corrected $t$-tests were performed using the MEANS option of the GLM procedure or the MEANS procedure from the SAS program system. Further post hoc analysis included correlation analysis between changes in power in each of the six spectral bands, analyzed during each of the three test sessions, with scores on the MBG, LSD, and PCAG subscales of the ARCI and the VAS scores obtained 45 minutes after injection of the test compound. Correlation analyses were only performed when the mixed regression ANOVA analysis showed a significant correlation effect, corrected for effects of TIME, LEAD, and TREATMENT. The dependent variable in all cases was the average spectral power; the independent variable was the score from the self-report scale.

\section{RESULTS}

There were no significant effects of morphine or placebo on heart rate or blood pressure; however, morphine caused a significant, dose-dependent decrease in pupillary diameter $(F=[11.3], d f=[2,8], p<.005$ for a main effect of TREATMENT). Post hoc tests showed that pupil size in each of the three drug conditions were signifcantly different from one another (placebo, 15 and 30 mg morphine). The results on the SDQ indicated that 12,3 , and 1 subjects identified the test compound as "blank" when given saline, $15 \mathrm{mg}$ and $30 \mathrm{mg}$ morphine, respectively. None of the subjects ever identified the test substance as any drug other than "dope."

Table 1 shows the effects of morphine on responses to the VAS. Scores for the five questions relating to positive effects (questions 1, 2, 4, 5, and 6) showed a gener- 


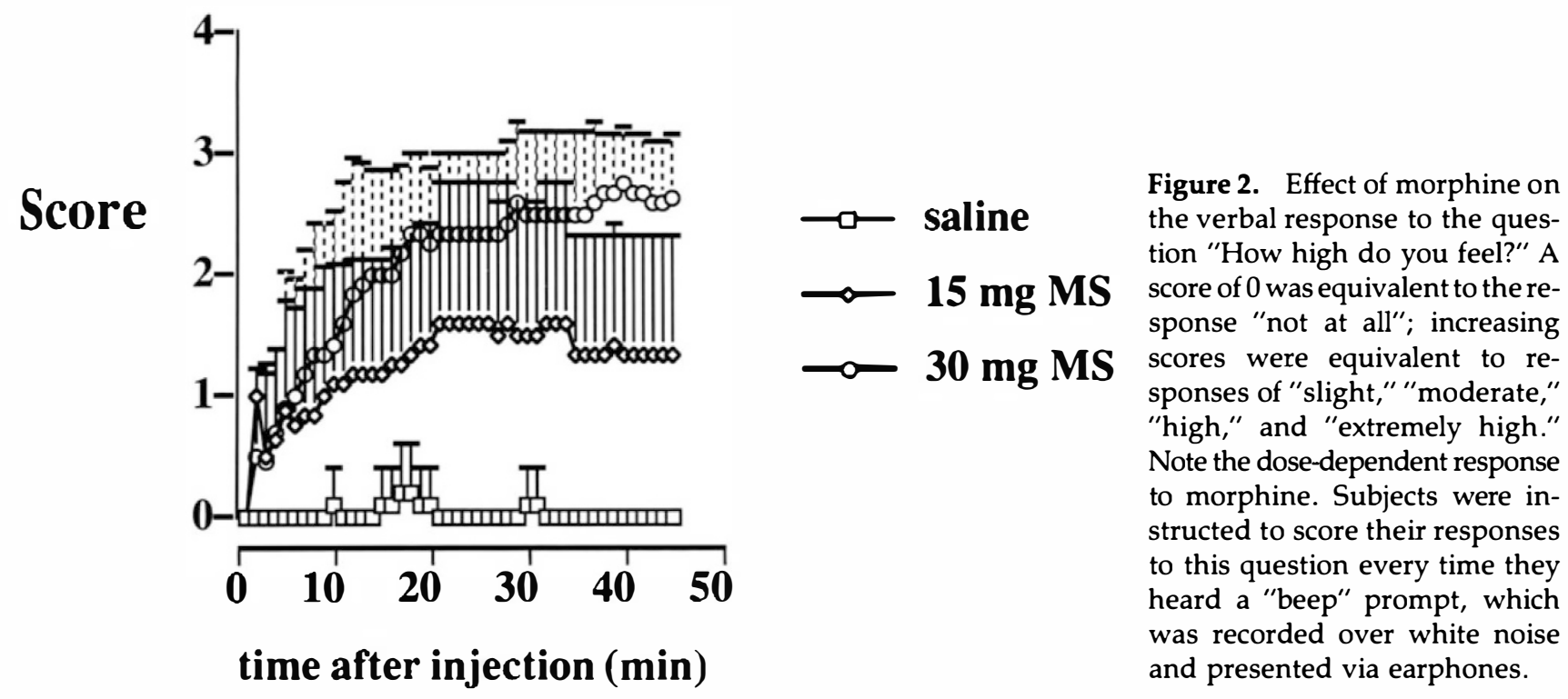

ally dose-dependent increase by morphine. The responses to these questions were highly correlated with one another. Correlation coefficients ranged from 0.74 to 0.995 between any two questions in each test condition. The lowest correlations involved question 6 ("How much do you want to take the drug again?"). There was no significant change from zero in response to the question "Does the drug have bad effects?" Coefficients of $\sim 0.4$ were obtained for the correlation of VAS score with alpha $a_{1}$ power after treatment with either dose of morphine; there were smaller correlation coefficients for other bands and test conditions. The correlation coefficients were not significant for any lead nor for the average of all leads but did achieve statistical signifcance for calculations including each lead separately in one analysis. Four subjects showed no response to 15 mg morphine; one also showed no response to $30 \mathrm{mg}$ morphine.

Figures 2 and 3 show subjective self-reports of the effects of morphine. The response (prompted by the "beep") to the question "How high do you feel?" was immediate (Fig. 2). The onset of the response was faster and the magnitude was larger when the higher dose of morphine was given. The ARCI revealed an increase in the MBG score in response to morphine (Fig. 3). The overall effect of TREATMENT was statistically signifcant $(F=[14.7], d f=[2,10], p<.001)$. Post hoc $t$-tests showed that the MBG scores after each of the two doses of morphine were significantly different from the response to placebo but not from each other. The effect of morphine on responses to the PCAG subscale was significant $(F=[6.19], d f=[2,10], p<.02)$, but there

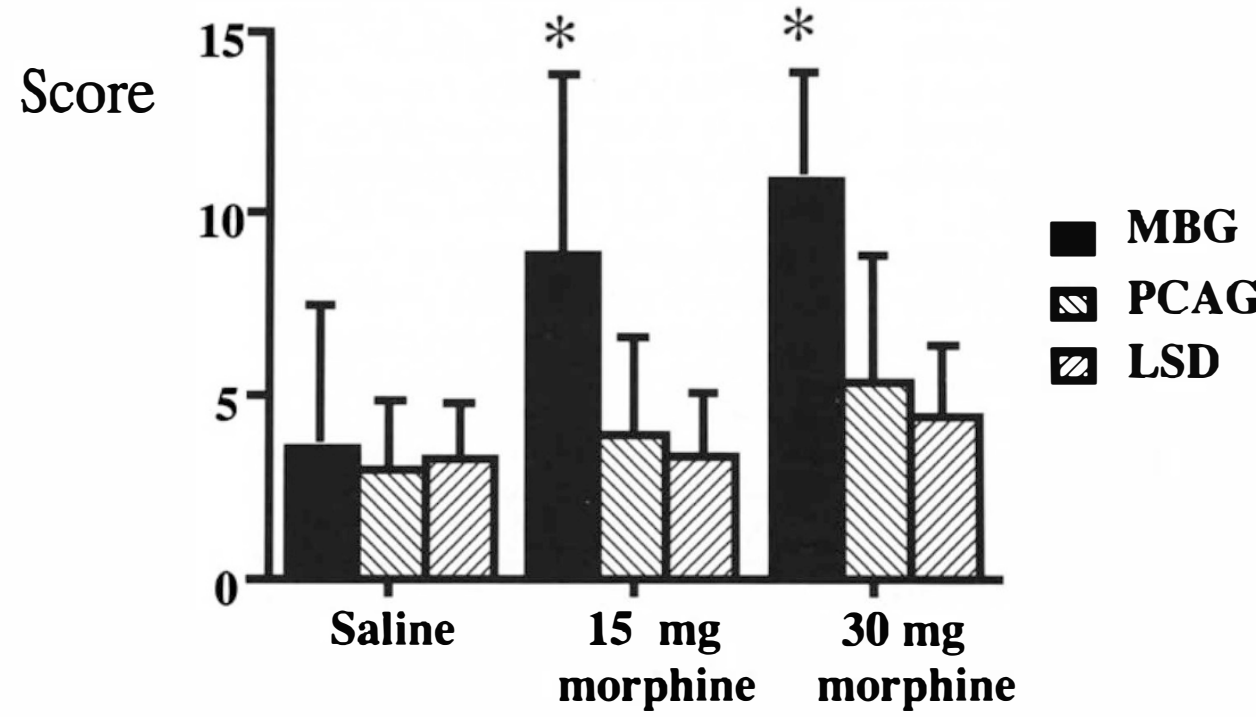

Figure 3. Effect of morphine on responses to the MBG, PCAG, and LSD subscales of the ARCI 45 minutes after the injection of the drug. Error bars indicate one standard deviation. * Significantly different from placebo $(p<.05)$ by Bonferroni-corrected matched pair $t$-test. 
Table 2. Analysis of Variance Effects of Drug Treatment, Lead, and Time on Change in EEG Spectral Power from Baseline

\begin{tabular}{|c|c|c|c|c|c|c|c|c|}
\hline \multirow[b]{2}{*}{ Band } & \multicolumn{2}{|c|}{ Treatment } & \multicolumn{2}{|c|}{ Time } & \multicolumn{2}{|c|}{ Time $\times$ Treatment } & \multicolumn{2}{|c|}{ Lead } \\
\hline & $F$ & $p(F)$ & $F$ & $p(F)$ & $F$ & $p(F)$ & $F$ & $p(F)$ \\
\hline Delta & 2.42 & 0.0905 & 4.13 & 0.0288 & 4.52 & 0.0046 & 0.45 & 0.9334 \\
\hline Theta & 6.96 & 0.0011 & 14.46 & $<0.0001$ & 4.40 & $<0.0029$ & 0.34 & 0.9764 \\
\hline Alpha $_{1}$ & 39.76 & $<0.0001$ & 17.95 & $<0.0001$ & 10.94 & $<0.0001$ & 0.81 & 0.6335 \\
\hline Alpha $_{2}$ & 3.21 & 0.0416 & 15.96 & $<0.0001$ & 3.03 & 0.0003 & 0.27 & 0.9912 \\
\hline Beta $_{1}$ & 7.45 & 0.0007 & 12.88 & $<0.0001$ & 5.22 & $<0.0001$ & 0.99 & 0.7762 \\
\hline Beta $_{2}$ & 10.24 & $<0.0001$ & 9.77 & $<0.0001$ & 5.29 & $<0.0001$ & 0.87 & 0.5694 \\
\hline$d f$ & \multicolumn{2}{|c|}{2,284} & \multicolumn{2}{|c|}{15,4260} & \multicolumn{2}{|c|}{30,4260} & \multicolumn{2}{|c|}{11,284} \\
\hline
\end{tabular}

Results of Multivariate ANOVA testing whether the different drug treatment conditions (TREATMENT), leads (LEAD), or time after injection (TIME) have statistically significant effects on the percent change in spectral power during the first 45 minutes after injection of test compound. Separate ANOVA procedures were performed for each spectral power band. The $p$ value shown for the effect of TME and the interaction of TIME and TREATMENT is the Greenhouse-Geisser adjusted $p$ value where appropriate.

were no significant post hoc comparisons. Morphine did not significantly affect responses on the LSD subscale $(F=[2.21], d f=[2,10], p>.1)$.

Table 2 shows the results of ANOVAs testing the effects of morphine on percent change in spectral power. There were no significant effects of LEAD nor of any interaction term involving LEAD. A confirmatory factor analysis showed that, for each treatment condition and band, a single factor explained $75 \%$ to $95 \%$ of the variance across TIME and LEAD. This factor was loaded equally into all leads.

Figures 4,5 , and 6 show the time course of the percent change in spectral power over the duration of the experiment. Delta power increased in the placebo condition (Fig. 4a). The increase was reversed by both doses of morphine, and was shown by a significant main effect of TIME and a significant interaction of TIME with TREATMENT. Individual ANOVAs at each time performed by repeated-measures-contrast ANOVA showed that, at most times after injection, there was a significant effect of TREATMENT. Figure $4 \mathrm{~b}$ shows the effects of morphine on percent change in theta power. There was a significant effect of TREATMENT as well as of TIME and a TREATMENT-with-TIME interaction. There was an increase in theta power during the first 12 and last 6 minutes of the experiment in response to $30 \mathrm{mg}$ morphine. Theta power decreased slightly in response to the saline and the injections of $15 \mathrm{mg}$ morphine.

Figure 5 shows the effects of morphine on alpha power, separated into two bands, low (alpha $\left.a_{1}\right)$ and high $\left(\right.$ alpha $\left._{2}\right)$. Both bands showed significant effects of TREATMENT and TIME, and a significantly TREATMENT-by-TIME interaction. These effects reflected an overall increase in alpha 1 power in response to morphine. The increase was greater after administration of morphine, particularly in response to the $30 \mathrm{mg}$ dose. In this case, the increase after 24 minutes was $30 \%$ to $40 \%$ over baseline. During the first 15 minutes after injection, there was an increase in alpha 2 power that dis- sipated more rapidly after the injection of saline than after the injection of morphine.

Figure 6 shows the results for beta power. According to repeated-measures ANOVA, both beta $a_{1}$ and beta $a_{2}$

$$
\text { Delta }(1 \leq f<6 \mathrm{~Hz})
$$

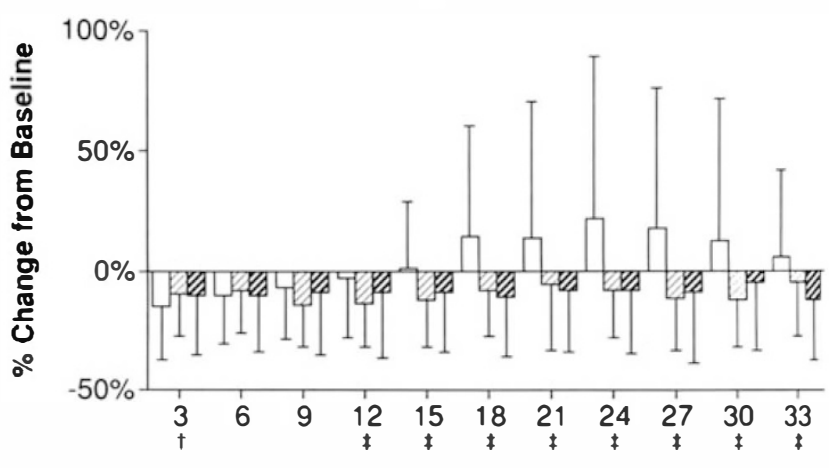

Theta $(6 \leq \mathrm{f}<8.5 \mathrm{~Hz})$

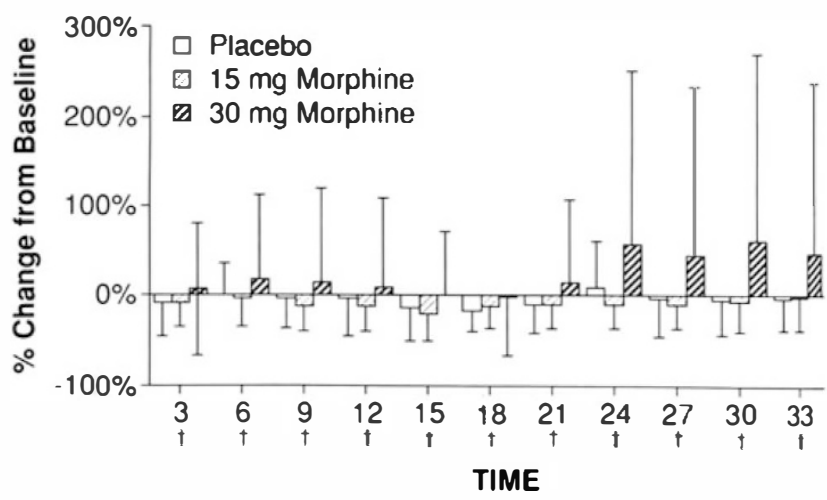

Figure 4. Effects of morphine on low-frequency spectral power. Figure shows change from baseline (pre-injection) epoch. Error bars indicate one standard deviation. ${ }^{\dagger}$ Response to $30 \mathrm{mg}$ of morphine differed significantly from the response to either $15 \mathrm{mg}$ morphine or placebo, $p<.05$ by Bonferronicorrected $t$-test. $\ddagger$ Responses to $15 \mathrm{mg}$ and $30 \mathrm{mg}$ of morphine differed significantly from the response to placebo but not from each other, $p<.05$ by Bonferroni-corrected $t$-test. 
Alpha $1(8.5 \leq f<10.5 \mathrm{~Hz})$

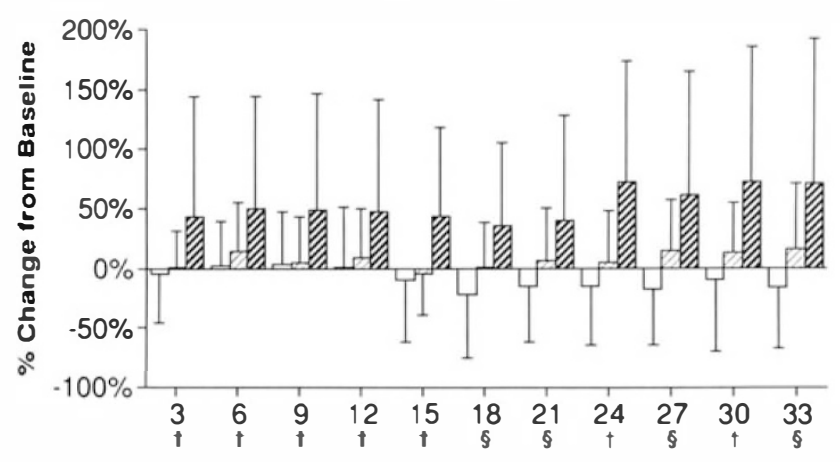

Alpha $_{2}(10.5 \leq f<12.5 \mathrm{~Hz})$

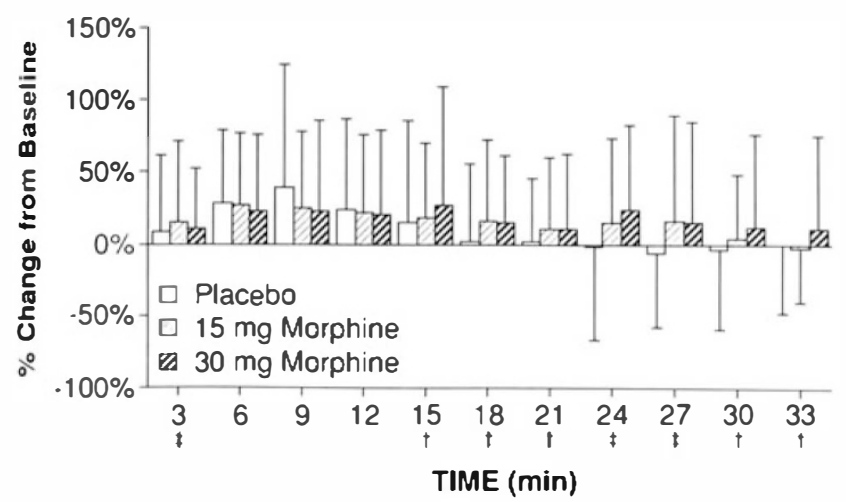

Figure 5. Effects of morphine on alpha frequency spectral power. Figure shows change from baseline (pre-injection) epoch. Error bars indicate one standard deviation. ${ }^{\dagger}$ Response to $30 \mathrm{mg}$ of morphine differed significantly from the response to either $15 \mathrm{mg}$ morphine or placebo, $p<.05$ by Bonferronicorrected $t$-test. $\ddagger$ Response to $15 \mathrm{mg}$ and $30 \mathrm{mg}$ of morphine differed significantly from the response to placebo but not from each other, $p<.05$ by Bonferroni-corrected $t$-test. $\S^{\mathrm{Re}}$ sponse to $15 \mathrm{mg}$ and $30 \mathrm{mg}$ of morphine and to placebo differed significantly from each other, $p<.05$ by Bonferronicorrected $t$-test.

power showed significant effects of TREATMENT, TIME and a TIME-by-TREATMENT interaction. There was an increase in beta $a_{1}$ during the first 15 minutes after injection of either placebo or morphine. The effect dissipated during the next 15 minutes; 24 minutes after the injection of $30 \mathrm{mg}$ morphine beta $a_{1}$ increased. Beta $a_{2}$ increased during the first 15 minutes after injection and dissipated during the rest of the experiment. The duration of the increase in beta 2 appeared to be dose related, lasting the longest after injection of $30 \mathrm{mg}$ morphine.

Table 3 shows the results of a test (by mixed ANOVA regression) for significant correlation between change in EEG spectral power from baseline and scores on the three subscales of the ARCI. The procedure tested correlation of the score on each subscale nested within TREATMENT and LEAD. Positive correlations

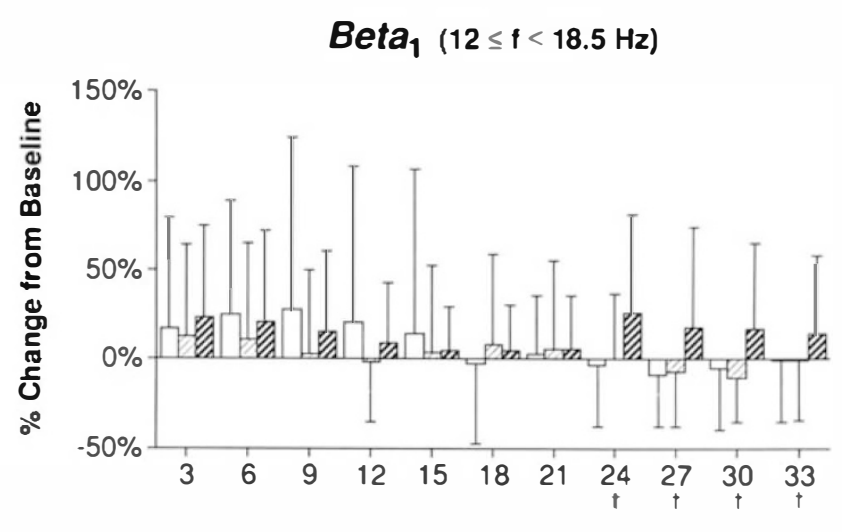

Beta $_{2}(18.5 \leq f<30 \mathrm{~Hz})$

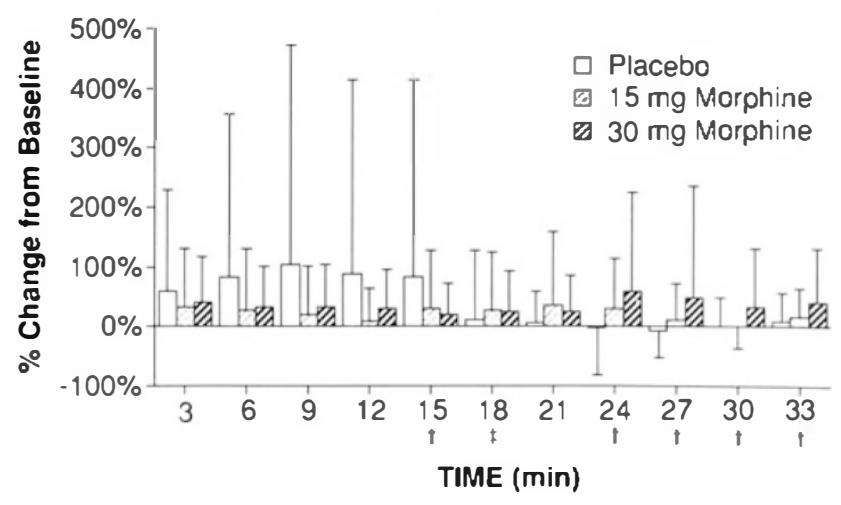

Figure 6. Effects of morphine on beta spectral power. Figure shows change from baseline (pre-injection) epoch. Error bars indicate one standard deviation. ${ }^{+}$Response to $30 \mathrm{mg}$ of morphine differed significantly from the response to either $15 \mathrm{mg}$ morphine or placebo, $p<.05$ by Bonferronicorrected $t$-test. ${ }^{\ddagger}$ Response to $15 \mathrm{mg}$ and $30 \mathrm{mg}$ of morphine differed significantly from the response to placebo but not from each other, $p<.05$ by Bonferroni-corrected $t$-test.

were found between change in theta, alpha, and beta power and MBG score; negative correlations were found with PCAG and the alpha $a_{1}$ and beta $_{2}$ bands. The scores on the LSD subscale showed no tendency for correlation with EEG measures. There was no correlation of changes in power in the delta band with any of the scores on the three subscales.

After the ANOVA, individual correlation analyses were performed. In these analyses, each factor (TREATMENT, LEAD, and TIME) were separated so that $(3 \times$ $12 \times 15=$ ) 540 correlation analyses were performed. Without the ANOVA to provide a protecting analysis, a correction for multiple comparisons (such as that of Bonferroni) would have been necessary and a value $p<$ $10^{-4}$ would have been the criterion for significance. With the covering analysis, we used an uncorrected $p$ value less than .05 as the criterion for significance.

Using the alpha $a_{1}$ band and lead $F_{7}$ as an example, there were $10 / 15$ and $12 / 15$ times when the percent 
Table 3. Significance of Covariance Between Scores on Subscales from the ARCI and Percent Change in EEG Spectral Power from Baseline

\begin{tabular}{|c|c|c|c|c|c|c|}
\hline \multirow[b]{2}{*}{ Band } & \multicolumn{2}{|c|}{ MBG } & \multicolumn{2}{|c|}{ LSD } & \multicolumn{2}{|c|}{ PCAG } \\
\hline & $F$ & $p(F)$ & $F$ & $p(F)$ & $F$ & $p(F)$ \\
\hline Delta & 0.40 & 0.992 & 0.59 & 0.9712 & 0.62 & 0.9578 \\
\hline Theta & 2.07 & 0.0070 & 0.26 & 1.000 & 0.48 & 0.9949 \\
\hline Alpha $_{1}$ & 4.74 & $<0.0001$ & 0.95 & 0.5549 & 3.17 & $<0.0001$ \\
\hline Alpha $_{2}$ & 1.67 & 0.0127 & 1.36 & 0.0901 & 0.54 & 0.9864 \\
\hline Beta $_{1}$ & 1.53 & 0.0325 & 0.75 & 0.8470 & 1.22 & 0.1888 \\
\hline Beta $_{2}$ & 1.33 & 0.0108 & 0.80 & 0.7897 & 2.85 & $<0.0001$ \\
\hline
\end{tabular}

The procedure tests for a significant correlation between change in EEG power in each band nested within the factors TREATMENT and LEAD but averaged over all 15 times after injection.

change in EEG power from baseline was significantly correlated $(p<.05)$ with the score on the MBG and PCAG subscales, respectively, in response to $30 \mathrm{mg}$ morphine. The correlations never achieved statistical significance in response to $15 \mathrm{mg}$ morphine or placebo. The correlation of change in EEG power vs. score on the LSD subscale never attained statistical significance. Figure 7 shows a typical example of the scatter plots illustrating the correlation. Similar findings were obtained from all of the other eleven leads from which data were analyzed.

\section{DISCUSSION}

As slow-wave sleep is associated with an increase in delta power and a decrease in alpha power (Walter 1959), morphine-induced decreases in delta power and increases in alpha power suggest that opioids produce arousal in subjects tolerant to the sedative effects of these drugs. This view is consistent with reports that morphine produces psychomotor activation in rodents (Babbini and Davis 1972; Shuster et al. 1975; Joyce and Iversen 1979). Because alpha $_{1}$ and beta $a_{2}$ power are negatively correlated with scores on the PCAG subscale and positively correlated with scores on the MBG subscale of the ARCI, reduced sedation (inferred from the PCAG score) accompanies positive affect (indicated by the MBG score) induced by morphine. These findings support and extend previous observations that morphine, like other opioids, induces insomnia in men who are not physically dependent upon opioids but have histories of opioid abuse (Kay et al. 1969).

Differences in the behavioral response to morphine, depending on the subject population, may explain some of the discrepancies observed with regard to EEG effects caused by or associated with morphine. It is well established that morphine is a sedating drug in normal subjects (Matejcek et al. 1988). Naive users also reported dizziness, nausea, and headache in response to morphine (Beecher 1959). Conversely, in experienced users,
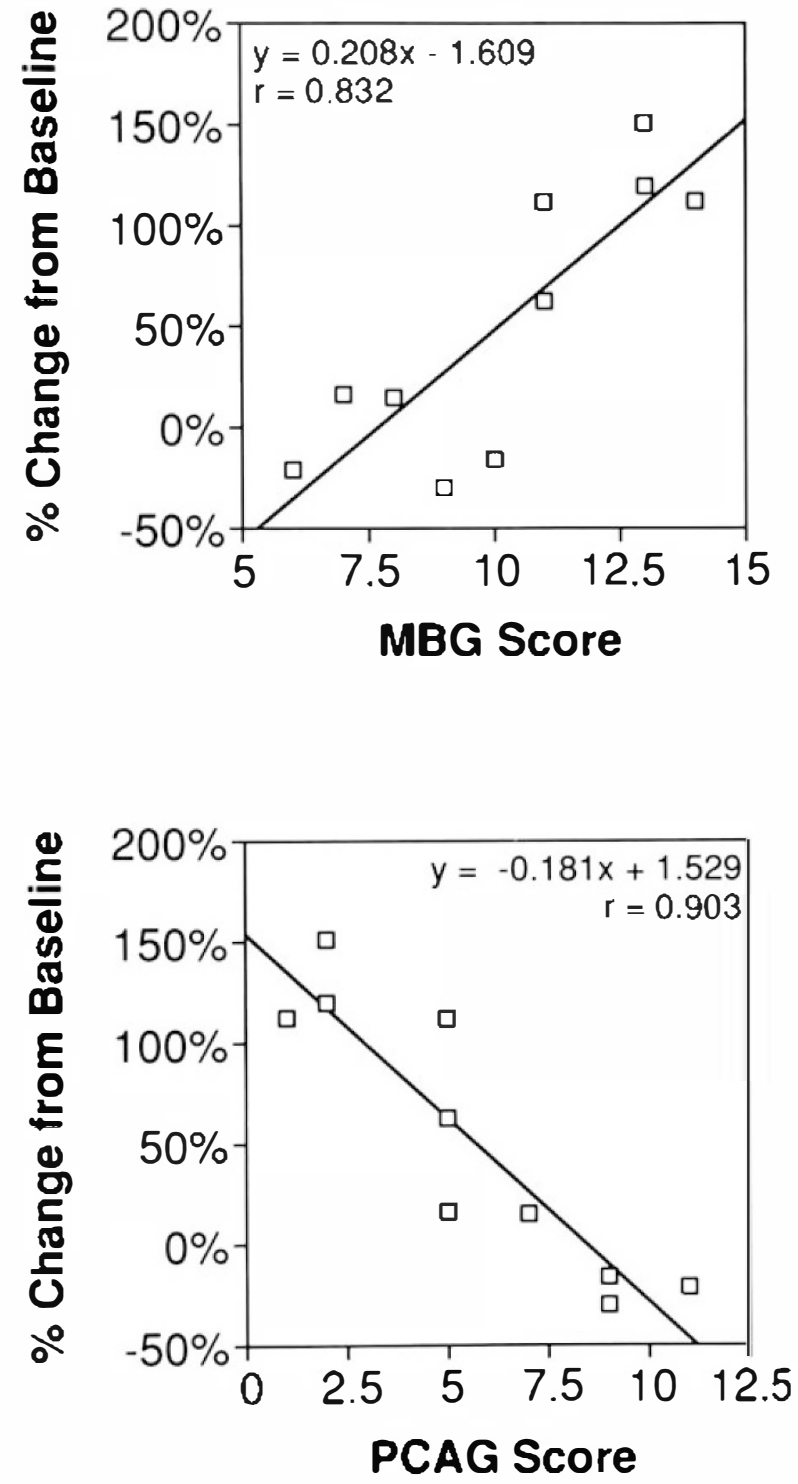

Figure 7. Correlation between change in EEG power in the alph $a_{1}$ band and scores on the MBG and PCAG subscales of the ARCI. MBG and PCAG were administered 45 minutes after injection. EEG data shown were measured 15 minutes after injection of $30 \mathrm{mg}$ morphine; EEG data were taken from a single lead $\left(F_{7}\right)$; other leads showed similar patterns. 
positive effects of the drug may keep subjects interested during an experimental procedure when they otherwise would lose interest and might fall asleep.

Although EEG activity recorded from a particular lead on the scalp does necessarily reflect cortical activity immediately below that lead, the absence of a significant effect of LEAD in this study is consistent with the finding that morphine produces an overall reduction of glucose metabolism throughout the entire cortex (London et al. 1990). These findings imply that positive effects of morphine on mood in polydrug abusers involve large cortical areas or subcortical regions rather than discrete loci in the cortex.

Positive correlations were found between the changes in alpha $a_{1}$, alpha $_{2}$, beta $a_{1}$, and beta $a_{2}$ power in response to $30 \mathrm{mg}$ morphine and scores on the MBG subscale of the ARCI. In contrast, negative correlations were observed between changes in alpha $a_{1}$ and beta $a_{2}$ and scores on the PCAG subscale. These correlations imply that positive effects of morphine, as measured by the MBG score, are related to increases in alpha and beta activity and to a reduction in sedation, as measured on the PCAG subscale. Although these correlations are consistent with the significant increases in alpha power produced by morphine, statistically significant increases in beta power were not observed. The lack of a consistent increase in beta power in response to morphinecontrasts with the effects of cocaine, which clearly increases beta activity (Berger 1931; Herning et al. 1985).

Despite marked differences in the behavioral and physiological activities of drugs of abuse, an emerging literature suggests that there are commonalities in the actions of these drugs, extending beyond their assignment to pharmacological classes. These commonalities include the ability to activate neuronal systems that produce positive affective states and attribute "incentive salience" (Robinson and Berridge 1993). In physiological terms, a variety of studies performed in animals have implicated central dopaminergic systems in the common behavioral effects of abused drugs (Hubner and Koob 1993). Studies in human volunteers have indicated that a common effect of drugs of abuse in experienced drug users is a reduction of cerebral glucose metabolism (London and Morgan 1993). The presenting findings with morphine extend observations with other drugs of abuse to indicate that an increase in alpha power may be another common action of drugs of abuse. Aside from the present and previous observations that morphine increases alpha power (Lukas et al. 1982; Lukas 1991), enhancement of alpha power has also been observed after administration of cocaine (Berger 1931) and doses of alcohol that had positive effects on mood (Lukas et al. 1986a, 1986b; Cohen et al. 1993; Lukas 1993).

Identification of a physiological process that underlies the behavioral aspects of drug abuse would be an important step in elucidating the addictive process. It appears that an increase in alpha power is related to the positive rewarding properties of morphine. Further investigation of the anatomical substrates of the druginduced increase in alpha power and its role in the acute and chronic effects of drugs of abuse appears to be warranted.

\section{ACKNOWLEDGMENTS}

The authors are indebted to J.H. Jaffe, M.D. for helpful discussions and support. We also thank M. Sano, M.D., Ph.D. and F.R. Snyder for participating in the early phases of data collection and analysis, R. Coppola, Ph.D. for helpful discussions and assistance with EEGSYS programs, and S. Patel for assistance in managing the raw EEG data and programming systems. We thank Cindy Ambriz and Theresa Doged for preparing the manuscript, and Bruce Vaupel, Ph.D. for review.

\section{REFERENCES}

DSM-III, Third Diagnostic and Statistical Manual, American Psychiatric Association (1980): Washington, D.C., American Psychiatric Press

Andrews HL (1941): Brain potentials and morphine addiction. Psychosom Med 3:399-409

Andrews HL (1943): Changes in the electroencephalogram during a cycle of morphine addiction. Psychosom Med 5:143-147

Babbini M, Davis WM (1972): Time-dose relationships for locomotor activity effects of morphine after acute or repeated treatment. Br J Pharmacol 46:213-224

Beecher HK (1959): Measurement of "mental clouding " and other subjective effects of morphine. In Beecher HK(ed), Measurement of Subjective Responses. Quantitative Effects of Drugs. New York, Oxford University Press, pp 201-210

BergerH (1931): Arch Psychiat Nervenkr 94:16-30. Translated in Gloor P (ed) 1969, Hans Berger on the electroencephalogram of man. Electroencephalogr Clin Neurophysiol Suppl 28, Amsterdam, Elsevier, pp 95-132

Berger H (1937): Arch Psychiatr Nervenkr 106:577-584. Translated in Gloor P (ed) 1969, Hans Berger on the electroencephalogram of man. Electroencephalogr Clin Neurophysiol Suppl 28, Amsterdam, Elsevier, pp 291-297

Bovill JG, Sebel PS, Wauquier A, Rog P, Schuyt HC (1983): Influence of high-dose alfentanil anaesthesia on the electroencephalogram: Correlation with plasma concentrations: Br J Anaesth 55:199S-209S

Bromm B, Meier W, Scharein E (1989): Pre-stimulus/poststimulus relations in EEG spectra and their modulations by an opioid and an antidepressant. Electroencephalogr Clin Neurophysiol 73:188-197

Cohen HL, Porjesz B, Begleiter H (1993): Ethanol-induced alterations in electroencephalographic activity in adult males. Neuropsychopharmacology 8:365-370

Coppola R (1979): Isolating low frequency activity in EEG spec- 
trum analysis. Electroencephalogr Clin Neurophysiol 46:224-226

Coppola R, Herrmann WM (1987): Psychotropic drug profiles: Comparisons by topographic maps of absolute power. Neuropsychobiology 18:97-104

De Andrés I, Caballero A (1989): Chronic morphine administration in cats: Effects on sleep and EEG. Pharmacol Biochem Behav 32:519-526

Fink M, Zaks A, Volavka J, Roubicek J (1971): Electrophysiological studies of opiates and antagonists in man. In Clouet DH (ed), Narcotic Drugs, Biochemical Pharmacology. New York, Plenum Press, pp 452-467

Fraser HF, Van Horn GD, Martin WR, Wolbach AB, Isbell $H$ (1961): Methods for evaluating addiction liability. (A) "Attitude" of opiate addicts toward opiate-like drugs, (B) a short-term "direct" addiction test. JPharmacol Exp Ther 133:371-387

Gibbs FA, Maltby GL (1943): Effect on the electrical activity of the cortex of certain depressant and stimulant drugsbarbiturates, morphine, caffeine, benzedrine and adrenalin. J Pharmacol Exp Ther 78:1-10

Haertzen CA (1974): An Overview of Addiction Research Center Inventory Scales (ARCI): An Appendix and Manual of Scales. Rockville, Dept. Health Education and Welfare Publication No. (ADM) 74-92

Herning RI, Jones RT, Hooker WD, Mendelson J, Blackwell L (1985): Cocaine increases EEG beta: A replication and extension of Hans Berger's historic experiments. Electroencephalogr Clin Neurophysiol 60:470-477

Hubner CB, Koob GF (1993): Neurobiological substrates mediating the reinforcing effects of psychomotor stimulant and opiate drugs. In London ED (ed), Imaging Drug Action in the Brain. Boca Raton, CRC Press, pp 1-48

Jaffe JH, Martin WR (1985): Opioid analgesics and antagonists. In Gilman AG, Goodman LS, Rall TW, Murad R (eds), The Pharmacological Basis of Therapeutics. New York, Macmillan, pp 491-531

Jasinski DR, Martin WR, Sapira JD (1967): Antagonism of the subjective, behavioral, pupillary, and respiratory depressant effects of cyclazocine by naloxone. Clin Pharmacol Ther 9:215-222

Jasinski DR, Martin WR, Hoeldtke R (1971): Studies of the dependence-producing properties of GPA-1657, profadol and propiram in man. Clin Pharmacol Ther 12:613-649

Jasper HH (1958); The ten twenty electrode system of the international federation. Electroencephalogr Clin Neurophysiol 10:371-375

Joyce EM, Iversen SD (1979): The effect of morphine applied locally to mesencephalic dopamine cell bodies on spontaneous motor activity in the rat. Neurosci Lett 14:207-212

Kay DC, Gorodetzky CW, Martin WR (1967): Comparative effects of codeine and morphine in man. JPharmacol Exp Ther 156:101-106

Kay DC, Eisenstein RB, Jasinski DR (1969): Morphine effects on human REM state, walking state and NREM sleep. Psychopharmacologia 14:404-416

Khazan N, Colasanti B (1971): EEG correlates of morphine challenge in post-addict rats. Psychopharmacologia 22: 56-63

London ED, Broussolle EPM, Links JM, Wong DF, Cascella
NG, Dannals RF, Sano M, Herning R, Snyder FR, Rippetoe LR, Toung TJK, Jaffe JH, Wagner HN, Jr. (1990): Morphine-induced metabolic changes in human brain: Studies with positron emission tomography and [fluorine-18]fluorodeoxyglucose. Arch Gen Psychiatry 47:73-81

London ED, Morgan MJ (1993): Positron emission tomographic studies on the acute effects of psychoactive drugs on brain metabolism and mood. In London ED (ed), Imaging Drug Action in the Brain. Boca Raton, CRC Press, pp 265-280

Lukas SE, Moreton JE, Khazan N (1982): Differential electroencephalographic and behavioral cross-tolerance to morphine and methadone in the $l$ - $\alpha$-acetylmethadol (LAAM)maintained rat. J Pharmacol Exp Ther 220:561-567

Lukas SE, Mendelson JH, Benedikt RA (1986a): Instrumental analysis of ethanol-induced intoxication in human males. Psychopharmacology (Berl) 89:8-13

Lukas SE, Mendel son JH, Benedikt RA, Jones B (1986b): EEG alpha activity increases during transient episodes of ethanol-induced euphoria. Pharmacol Biochem Behav 25: 889-895

Lukas SE (1991): Brain electrical activity as a tool for studying drugs of abuse. In Mello NK (ed), Advances in Substance Abuse. Behavioral and Biological Research. London, Jessica Kingsley Publishers, pp 1-90

Lukas SE (1993): Advanced electrophysiological imaging techniques for studying drug effects. In London ED (ed), Imaging Drug Action in the Brain. Boca Raton, CRC Press, pp 389-404

Martin WR (1983): Thoughts about the relevance of neurochemistry, neurophysiology and neuropsychopharmacology to the social problems of drug abuse. Drug Alcohol Depend 11:9-10

Matejcek M, Pokorny R, Ferber G, Klee H (1988): Effect of morphine on the electroencephalogram and other physiological and behavioral parameters. Neuropsychobiology 19:202-211

Preston KL, Bigelow GE, Liebson IA (1988): Buprenorphine and naloxone alone and in combination in opioid-dependent humans. Psychopharmacology (Berl) 94:484-490

Robins LN, Helzer JE, Croughan J, Ratcliff KS (1981): National Institute of Mental Health Diagnostic Interview Schedule: Its history, characteristics, and validity. Arch Gen Psychiatry 38:381-389

Robinson TE, Berridge KC (1993): The neural basis of drug craving: An incentive-sensitization theory of addiction. Brain Res Rev 18:247-291

Scott JC, Cooke JE, Stanski DR (1991): Electroencephalographic quantitation of opioid effect: Comparative pharmacodynamics of fentanyl and sufentanil. Anesthesiology 74:34-42

Sebel JS, Bovill JG, Wauquier A, Rog P (1981): Effects of highdose fentanyl anesthesia on the electroencephalogram. Anesthesiology 55:203-211

Shuster L, Webster GW, Yu G (1975): Increased running response to morphine in morphine-pretreated mice. J Pharmacol Exp Ther 192:64-67

Smith NT, Dec-Silver H, Sanford TJ, Jr., Westover CJ, Jr., Quinn ML, Klein F, Davis DA (1984): EEGs during highdose fentanyl-, sufentanil-, or morphine-oxygen anesthesia. Anesth Analg 63:386-393 
Volavka J, Zaks A, Roubicek J, Fink M (1970): Electrographic effects of diacetylmorphine (heroin) and naloxonein man. Neuropharmacology 9:587-593

Volavka J, James B, Reker D, Mallya A, Cho D, Pevnick J (1979): EEG and other effects of naltrexone and heroin in man. Pharmakopsychiatr Neuropsychoparmakol 12: 79-85

von Felsinger JM, Lasagna L, Beecher HK (1955): Druginduced mood changes in man. JAMA 157:1113-1119

Walter WG (1959): Intrinsic rhythms of the brain. In Field J, Magoun HW, Hall VE (eds), Handbook of Physiology. Washington, D.C., American Physiology Society, pp 279-298

Wauquier A, Bovill JG, Sebel PS (1984): Electroencephalographic effects of fentanyl-, sufentanil-, and alfentanil anaesthesia in man. Neuropsychobiology 11:203-206

Wikler A (1952): Pharmacologic dissociation of behavior and
EEG "sleep patterns" in dogs: Morphine, $N$-allylnormorphine, and atropine (19345). Proc Soc Exp Biol Med 79: 261-265

Wikler A (1954): Clinical and electroencephalographic studies on the effects of mescaline, $\mathrm{N}$-allylnormorphine and morphine in man. J Nerv Ment Dis 120:157-175

Young GA, Steinfels GF, Khazan N (1980): Narcotic abstinence in dependent rats: EEG and behavioral correlates. Pharmacol Biochem Behav 13:115-119

Young GA, Khazan N (1984): Differential neuropharmacological effects of $m u, k a p p a$, and sigma opioid agonists on cortical EEG power spectra in the rat. Neuropharmacology 23:1161-1165

Young GA, Khazan N (1986): Differential protracted effects of morphine and ethylketocyclazocine challenges on EEG and behavior in the rat. Eur J Pharmacol 125:265-271 